\title{
EXPERIÊNCIAS INDESEJÁVEIS: ALGUNS CASOS DE ASSÉDIO SEXUAL NO FUTEBOL
}

\author{
UNDESIRABLE EXPERIENCES: SOME CASES OF SEXUAL HARASSMENT IN \\ FOOTBALL
}
EXPERIENCIAS INDESEABLES: ALGUNOS CASOS DE ACOSO SEXUAL EN EL FÚTBOL

\section{Everton de Albuquerque Cavalcanti ${ }^{\star}$, André Mendes Capraro**}

\section{Palavras chave:}

História.

Memória.

Atletas.
Resumo: 0 objetivo deste trabalho é retratar as memórias de dois atletas e dois exatletas profissionais de futebol, no que diz respeito às suas experiências com relação a casos de assédio sexual nas categorias de base de clubes brasileiros. Nos pautamos metodologicamente pela História Oral, que é um método de pesquisa que se utiliza de entrevistas com sujeitos que vivenciaram experiências que de alguma forma podem servir para analisarmos um determinado objeto de estudo. Compreendemos então que a oralidade trata da singularidade de cada narrativa, visto que as histórias são contadas a partir do ponto de vista de quem, de alguma forma as vivenciou. Entretanto, a reincidência de casos referentes a um problema social em evidência que anteriormente permanecia velado reitera que esses casos já aconteciam, e por vezes passavam despercebidos pela mídia e pelas autoridades responsáveis em coibir esse tipo de ação criminosa.
Keywords:

History.

Memory.

Athletes.

Palabras clave: Historia.

Memoria.

Atletas.
Abstract: This work describes the memories of two professional athletes and two former professional athletes about their experiences with cases of sexual harassment in the base categories of Brazilian football clubs. We used oral history - a research method that employs interviews with subjects who had experiences that can somehow contribute to analyses of a particular object of study. Therefore, we understand that orality addresses the singularity of each narrative, since the stories are told from the point of view of those who experienced them. However, the recurrence of cases concerning a previously unacknowledged social problem reiterates that these cases were already happening and sometimes went unrecognized by the media and the authorities responsible for curbing this type of criminal action.

Resumen: El objetivo de este trabajo es retratar las memorias de dos atletas y dos exatletas profesionales del fútbol en lo que se refiere a sus experiencias con relación a casos de acoso sexual en las categorías de base de clubes brasileños. Nos pautamos metodológicamente por la historia oral, que es un método de investigación que utiliza entrevistas con sujetos que han vivido experiencias que de alguna forma pueden servirnos para analizar un determinado objeto de estudio. Comprendemos, entonces, que la oralidad trata de la singularidad de cada narrativa, ya que las historias son contadas desde el punto de vista de quien, de alguna forma, las ha vivido. Sin embargo, la reincidencia de casos referentes a un problema social en evidencia hoy y que anteriormente permanecía velado, reitera que esos casos ya ocurrían, y a veces pasaban desapercibidos por los medios y por las autoridades responsables en cohibir ese tipo de acción criminal.
*Universidade Federal de Mato Grosso do Sul. Corumbá, MS, Brasil. E-mail: profevertoncavalcanti@gmail. com

**Universidade Federal do Paraná Curitiba, PR, Brasil. E-mail: andrecapraro@onda.com.br

Recebido em: 27-07-2018 Aprovado em: 06-07-2019 Publicado em: 05-12-2019

DOI: hitps://doi.org/10.22456/1982-8918.85215 (c) (1) (8) Licence 


\section{INTRODUÇÃO}

Neste texto, abordamos histórias de futebolistas que vivenciaram ou presenciaram casos de assédio sexual. Tal questão surge como problemática a partir do momento em que a mídia e o senso comum reconhecem veladamente situações pontuais, que durante anos não tinham comprovação e punição dos responsáveis, e que recentemente vieram à tona através de reportagens que retrataram ocorrências de abuso na ginástica artística' ${ }^{1}$.

Reiteramos que por se tratar de um problema social que se utiliza do esporte como meio, essa realidade não é exclusiva de uma modalidade, como podemos perceber com os próprios casos da ginástica. Porém, neste texto pretendemos observar o futebol enquanto espaço em que alguns indivíduos se inserem com a pretensão de cometer crimes dessa natureza.

Se outrora buscávamos perifericamente identificar tais dificuldades por meio de fontes como jornais e documentos, já é possível ampliarmos nossa perspectiva de reconhecimento do meio futebolístico pelas histórias de quem viveu e pode nos levar a fundo na centralidade dos problemas oriundos de uma prática representativa financeiramente e socialmente.

Compreendemos que as histórias apresentadas contemplam um tema polêmico que precisa ser discutido pelo ponto de vista de atletas e ex-atletas, que porventura tenham presenciado situações referentes a esse problema social.

Portanto, o objetivo deste trabalho é retratar as memórias de atletas e ex-atletas profissionais de futebol, no que diz respeito às suas experiências com relação a casos de assédio sexual nas categorias de base de clubes brasileiros.

Nos pautamos metodologicamente pela História Oral, que para Alberti (2003) é um método de pesquisa que se utiliza de entrevistas com sujeitos que vivenciaram experiências que de alguma forma podem servir para analisarmos um determinado objeto de estudo. Pois então, a História Oral é responsável pela construção de suas fontes, que poderão ser agrupadas em um acervo a ser consultado. Possibilita o estudo de diferentes grupos a partir de relatos dos sujeitos que dele fizeram parte.

$\mathrm{Na}$ História Oral, a narrativa não tem fim em si mesma. A entrevista que por vezes resulta de um diálogo bipolar é uma constante troca de olhares, resultado de uma conversa construída entre dois sujeitos face a face, em que não existe observador e observado, estão separados por um microfone, no qual o narrador tenta compreender o que o pesquisador busca, modelando seu discurso a partir de tais constatações (PORTELLI, 2010).

Patai (2010) revela que a História Oral se interpõe no entrecruzamento de subjetividades. São as percepções do entrevistador e do entrevistado, a influência cultural sofrida por ambos, as memórias de quem lembra em consonância com as questões de quem pergunta, os recuos conscientes de quem não sabe se deve falar sobre determinado assunto e os estímulos que demonstram interesse em ouvir. Logo, a História Oral não está alheia às intervenções de quem dela participa, não trata apenas de enunciar e receptar discursos, mas relaciona-se à capacidade de se estabelecer uma relação humana que propicie sua efetivação. A relevância

1 Várias notícias evidenciaram as denúncias de abuso sexual cometido pelo ex-técnico da seleção brasileira Fernando de Carvalho Lopes. Seguem algumas reportagens a respeito todas acessadas em set. 2019:

http://interativos.globoesporte.globo.com/ginastica-artistica/abuso-na-ginastica/especial/escandalo-na-ginastica https://www.metropoles.com/brasil/tecnico-da-selecao-de-ginastica-artistica-filmava-abusos-sexuais 
da interação humana em entrevistas decorre do fato de que as histórias são projetadas de forma específica e em determinadas circunstâncias.

Dessa forma, propomos uma discussão metodológica acerca da História Oral, que toma como mote depoimentos acerca do tema assédio, a fim de explorar as potencialidades desse referencial para a discussão de questões acerca de um problema social que parece permanecer obscuro no contexto esportivo.

A partir disso, realizamos duas entrevistas com atletas profissionais e duas com exatletas profissionais de futebol, preservando o anonimato dos participantes, devido à abordagem de uma temática polêmica. Na passagem do oral para o escrito, optamos por trabalhar com a transcrição, eliminando vícios de linguagem, porém, preservando a originalidade da produção inicial (ALBERTI, 2003).

As entrevistas foram realizadas individualmente ${ }^{2}$, de acordo com a disponibilidade dos sujeitos e nos espaços indicados por eles. Preparamos um roteiro semiestruturado com uma pergunta-base solicitando que o entrevistado contasse sua história livremente. Em seguida, abordamos em perguntas específicas a trajetória de cada colaborador (estudamos a trajetória de cada indivíduo participante da pesquisa através de dados da internet), sendo que, no momento em que realizamos as questões, acrescentamos novos questionamentos que achamos pertinentes à temática da pesquisa.

A escolha do número de participantes se deu pelo tempo disponível para a realização da pesquisa, visto que foram entrevistas relativamente longas, demandando tempo para transcrição e análise. Além do que, a circularidade dos atletas impediu que realizássemos algumas entrevistas que estavam programadas. Já a escolha pelos atletas se deu de acordo com a indicação de possíveis entrevistados, bem como de acordo com a indicação subsequente dos próprios entrevistados.

\section{OS BASTIDORES DE UMA REALIDADE VELADA NO FUTEBOL}

Compreendemos que as memórias aqui retratadas não dizem respeito à totalidade de relações que são estabelecidas nesse meio. Porém, como propõe Halbwachs (2013), pensamos que essas histórias e suas recorrências ajudam-nos a entender a estrutura do futebol de forma ampla e específica ao mesmo tempo, já que tais experiências contemplam a perspectiva da comunidade de atletas de futebol, assim como cada história tem suas particularidades que ajudam a definir as problemáticas no ambiente futebolístico. Acerca de tal perspectiva nosso colaborador afirmou:

Aí eu fui, na verdade para o Guarani, até saí do campeonato e fui direto com o ônibus do Guarani mesmo, já nem voltei pra casa, fui direto com eles. Cheguei lá, treinei bem uma semana, superbem, treinei bem a segunda semana, estava pronto para assinar, aí a gente perdeu um amistoso, daí o clima já não ficou tão bom, mas ainda assim estava pronto para assinar, beleza, estava até de titular já. Aí o diretor da categoria de base lá, ele na verdade, essa é uma história bem complicadinha porque o diretor da categoria de base ele era, na verdade ele assediava os atletas, daí assim, eu estava no meu quarto e tal, aí ele chegou, bateu na porta, eu estranhei porque já era de noite, aí ele falou: "Vamos lá, quero te mostrar a banheira do profissional", não sei o que e tal. Daí eu fiquei meio assim, falei: "Como assim?!". Eu acho que eu tinha uns 15, 14, para 15, uns 15 anos eu já 
tinha. Aí fiquei meio assim, fui meio que lá só pra ver, mas já meio que estranhando a intenção dele, daí ele falou: "Entra aí tomar um banho", eu falei: "Não, capaz, tranquilo". Aí nisso ele viu que eu recusei e fui voltando para o meu quarto, daí ele jogou a real, falou assim: "Olhe, tal e tal jogador aqui do profissional só estão lá porque eu coloquei. Se você quiser eu trago o contrato profissional para você assinar aqui agora e aí você já assina o contrato de profissional, já profissionaliza, vai jogar para o juvenil, infantil, juvenil, mas é uma questão de dois anos para estar no profissional, já estar com o contrato feito", mas né, lógico que ele queria alguma coisa. Aí eu falei que não, peguei minha mala, já estava de noitão assim, arrumei toda a minha mala, não era nem 6h da manhã eu estava saindo de lá, nem contei para ninguém, sai de lá, arrumei um ônibus e vim embora. Aí vim embora, mas na verdade eu deveria ter falado para outros diretores, mas não tinha ainda a noção do que eu podia fazer ou não (JOGADOR 2, 2016).

Nessa experiência relatada, o jogador 2, ex-atleta que, dentre os participantes desta pesquisa, se mostrou o mais conformado com o encerramento precoce da carreira, se mostrou também corajoso ao levantar essa realidade que viveu quando era adolescente. Essa perspectiva apresentada mostra como as fontes orais proporcionam novos dados que nos permitem analisar com profundidade os espaços nos quais as fontes oficiais, por vezes, não conseguem chegar.

Notamos, então, que a relação de forças estabelecidas nesse caso é desproporcional para o atleta, visto que o dirigente detém poder suficiente para decidir o direcionamento da carreira dos jovens das categorias de base do clube. Novamente percebemos como a memória é uma análise do passado no presente, já que o próprio colaborador afirma que deveria ter conversado com outros dirigentes acerca do caso.

A partir de Damo (2005) compreendemos que a imaturidade desses jovens atletas contribuiu para o processo de ocultamento dessa realidade, assim como o fato do futebol ser praticado em diversos lugares do Brasil permite-nos pensar como esses problemas sociais podem reincidir nas categorias de base e até mesmo na iniciação esportiva.

Nesse sentido, as memórias se mostram um caminho alternativo para a compreensão dessas obscuridades que assolam o esporte e que são deixadas de lado, sem a devida atenção dos responsáveis. Pela perspectiva da subjetividade em Portelli (1996; 1997), a experiência retrata a realidade vivida através de um caso ocorrido com nosso colaborador e da suposição de outros, já que o próprio abusador afirmou ter feito o mesmo em mais de uma oportunidade.

A partir de Smith (2012) buscamos então as razões para a sua formação narrativa, se mostrando despreocupado quanto à polêmica. 0 jogador 2 evidencia 0 sentimento de indignação para com essas estratégias dos dirigentes, compreendendo que o futebol não é permeado somente pela meritocracia técnica, mas por essas transgressões pouco desveladas por aqueles que deveriam fiscalizar essas ações.

O colaborador ainda nos esclarece a ideia de Portelli (2010), que compactua com a perspectiva de que o lapso temporal entre os fatos e o momento da entrevista proporciona uma reinterpretação das experiências, promovendo esclarecimentos de como a história poderia ser diferente. Acerca dessa questão, ele acrescenta:

Nisso que mandam embora, eu fui para a Portuguesa Santista, daí ali eu assinei contrato e disputei um Paulista, daí estava o Axel - profissional - daí ali eu disputei um paulista profissional antes de fechar o contrato para fora. Daí estava o Axel, Marcelo Passos, que tinha sido campeão no Santos, Axel pelo São Paulo. Só que 
ali também tinha outro cara que dava em cima de jogador, entendeu? Daí o cara começou a me queimar porque eu mandei ele ir a merda e falei que não ia fazer nada, entendeu? E era outro cara que fechava contrato com uns mais novinhos por esquema, sabe? (JOGADOR 2, 2016).

A partir de Damo (2008), notamos como as características do futebol-espetáculo estabelecem regras internas que se adaptam de acordo com as necessidades daqueles que se estabelecem enquanto detentores do poder no clube. Dessa forma, os indivíduos que não compactuam com tais normas acabam passando por um processo de circulação nesse espaço, tentando se estabelecer e se enquadrar pelos próprios méritos no meio futebolístico.

Compreendemos em Damo (2005) que as características dos ocultamentos de problemas sociais no futebol revelam as particularidades dos diversos "futebóis" que se expressam nas configurações estabelecidas nos diferentes níveis em que esse esporte acontece. São situações que nos remetem ao entendimento do futebol enquanto espaço dinâmico que se concretiza a partir de uma série de questões, dentre elas os problemas relacionados ao assédio sexual.

Acreditamos que as experiências do jogador 2 nos aproximam do entendimento dessa conjuntura, já que seu discurso evidencia a localização de quem não estabelece relações no futebol que pudessem prejudicá-lo. Portanto, transmite a relevância de Candau (2014) quanto a sua posição temporal e espacial no momento em que retrata sua história, que, fora do campo futebolístico, permitiu esse caráter despreocupado quanto à repercussão que sua narrativa poderia alcançar.

Ao estabelecer uma relação de confronto com o dirigente em questão, demonstrou como as relações de poder ${ }^{3}$ são determinantes na busca por espaço em um contexto concorrido, no qual quem não se enquadra acaba sendo preterido por quem aceita essas condições. Como a própria narrativa preconiza, esse processo de exclusão é implícito e velado, no qual as ações dos abusadores tratam de tornar tais medidas imperceptíveis para quem circula no meio do futebol, o que dificulta medidas de divulgação e exposição desses problemas.

A narrativa trata ainda a questão como cíclica no futebol, visto que, apesar de alguns recusarem essas propostas de assédio, outros acabam cedendo e ocupando os espaços disponibilizados por esses dirigentes. Esse discurso externo ao contexto esportivo demonstra como a constituição desses crimes é oportunizada pela posição desses indivíduos, que se aproveitam da representatividade do futebol para agir de acordo com sua convencionalidade.

Ao citar os exemplos de jogadores consagrados que já passaram por clubes representativos no futebol brasileiro, notabiliza essa ideia de que o capital simbólico ${ }^{4}$ é relevante no processo de quem se mantém nesse espaço, já que os dirigentes não assediavam os indivíduos reconhecidos. Enquanto isso, o jogador 2, um atleta jovem, passava por determinadas situações por não ter o mesmo potencial de poder de seus colegas.

A estrutura e a subjetividade estão relacionadas, já que é possível identificar esses problemas pela perspectiva dos atletas anônimos, sem espaço midiático para contrapor publicamente essa realidade estrutural, enquanto que no mesmo espaço circulam indivíduos

3 [...] a palavra poder, na esfera social, seja pelo indivíduo ou instituição, se define como "a capacidade de este conseguir algo, quer seja por direito, por controle ou influência. O poder é a capacidade de se mobilizar forças econômicas, sociais ou políticas para obter certo resultado [...]" (Blackburn, 1997: 301). Muito embora, de acordo com o autor, esse poder possa ser exercido de forma consciente ou não, e/ ou, frequentemente, exercido de forma deliberada (FERREIRINHA, RAITZ, 2010).

4 O capital simbólico não é outra coisa senão o capital, qualquer que seja a sua espécie, quando percebido por um agente dotado de categorias de percepção resultantes da incorporação da estrutura da sua distribuição, quer dizer, quando conhecido e reconhecido como algo de óbvio (BOURDIEU, 1992). 
capazes de mudar essa perspectiva, mas que não são afetados por ela, justamente pela capacidade de alterar o cenário com a representatividade construída no esporte.

Nesse sentido, Halbwachs (2013) evidencia que a construção social do discurso estabelece uma ideia de memória coletiva que afeta os indivíduos que compactuam de uma realidade semelhante, mesmo suas histórias apresentando especificidades que as diferenciem subjetivamente. Ele continua sua narrativa esclarecendo:

Eu vi assim, comigo foi em duas situações, no Guarani, que eu peguei minhas coisas e fui embora e essa vez, esse cara da Portuguesa Santista ele tentava, mas ele não ameaçava, sabe? Mas ele tentava com todos que eram mais jovens, inclusive dos juniores também, oferecia contrato pra ir lá no apartamento dele. Do Guarani eu tive que me virar porque eu estava no alojamento do clube, então ele ia ficar me enchendo o saco o resto da vida se eu ficasse ali. Na Portuguesa foi mais fácil porque eu tinha o meu apartamento e ele tinha o dele, então ele não ia lá no meu apartamento encher o saco e já era mais velho, então tinha como me defender bem mais fácil. Agora uma que eu vi que era bem complicada, inclusive o cara foi preso até, era numa escolinha que quando eu estava sem time eu ia ali treinar e ele aliciava meninos de 11, 12 anos, 10 anos. Inclusive um, ele chegou a namorar com a mãe e ficava com o menino e pegava o menino. Ai o menino depois de 16 anos, 17 anos de idade teve coragem de contar, daí o rapaz foi preso, daí que 0 cara foi preso. Então ele passou uns três, quatro anos da vida que 0 cara abusava dele, então bem complicado. E assim, todo mundo sabia, entendeu? Se ele tinha 10,11 anos, eu tinha meus 14 , só que eu ele respeitava porque ele conhecia meu pai, entendeu? Os dois eram do meio do futebol e ele conhecia meu pai. Então meu pai não tinha ideia disso, eu sabia, mas eu era criança também, nem pensava em denunciar na época, nem nada e daí depois acabou sendo preso e eu nem sei se não está até hoje (JOGADOR 2, 2016).

Nosso colaborador esclarece acerca das mudanças que o tempo proporciona, acrescentando maturidade, reinterpretando as experiências passadas e compreendendo como lidar com fatos semelhantes no futuro. Pensando na ideia de que as memórias dolorosas são reconhecidas (POLLAK, 1989), detalha como foram suas experiências no Guarani e na Portuguesa Santista, fazendo um paralelo das diferenças dos acontecimentos nos dois clubes. No primeiro, enquanto era adolescente, não tinha discernimento suficiente para contrapor a situação, já no segundo, evidencia que sua formação humana e a chegada da fase adulta propiciaram a chance de se defender com mais facilidade.

Essas situações revelam como esse meio, independentemente do nível de atuação, contempla essas obscuridades que afetam a sociedade de um modo geral, já que, nesses casos, o futebol é apenas o espaço no qual determinados sujeitos se inserem para cometer esses desvios de conduta. Compreendendo a formação da narrativa em Smith (2012), identificamos que, nesse momento da entrevista, o colaborador estava tenso, demonstrando como essas lembranças negativas ocupam espaço e permanecem detalhadamente na memória, colaborando na reconstrução e reinterpretação dessas histórias passadas no presente (PORTELLI, 2010). Ele continua:

E lá no Guarani quando eu disse não, teve um menino que foi levado junto, lembra que eu fui num campeonato e do campeonato que eu fui pra lá? Fui escolhido e fui para lá, foi eu e mais um escolhido e esse outro menino ele era de muito boa aparência, inclusive ele era modelo também e esse menino aceitou a proposta do cara e ficou lá uns três, quatro anos (JOGADOR 2, 2016). 
Percebemos como esses sujeitos se valem da posição que ocupam no clube, recorrendo ao capital simbólico para se aproveitar de meninos menores de idade que têm o objetivo de se tornar atletas profissionais. Na narrativa fica evidente novamente que 0 abuso sexual contra menores no meio futebolístico é recorrente, visto que por mais que ele não tenha aceitado as condições do aliciador, outro sujeito se submeteu a isso, demonstrando que essa demanda se renova com o interesse de novos garotos da base de integrarem a categoria principal.

Através de Spaggiari (2015) percebemos que, nos casos em que o sujeito sai do ambiente de proteção familiar e vai para o alojamento do clube com a anuência dos próprios responsáveis, a intenção é que a carreira futebolística seja um projeto que visa mudar a realidade social e financeira de toda a família. Nesses casos, a imaturidade dos jovens e a posição de poder dos aliciadores tornam o espaço propício para esse tipo de crime, muito embora, nesse caso, nosso colaborador não tenha aceitado a proposta, consequentemente deixando o clube.

A instituição fica refém desses dirigentes que se aproveitam do contexto em que estão inseridos para cometerem esses crimes, prejudicando o clube, tanto judicialmente quanto pela constituição de critérios duvidosos no momento de escolher os atletas que devem integrar as categorias de base e o elenco profissional.

As narrativas de nosso colaborador são polêmicas, mas o discurso trata das questões de forma direta, e por mais que não haja ressentimento no relato, nos mostra como as memórias que retrata são as que marcaram sua vida (PORTELLI, 2010). Nesse sentido, essas obscuridades retratadas de forma velada pela mídia e pelo senso comum tomam outra proporção quando as refletimos a partir das histórias de quem participou efetivamente desse contexto.

Além disso, ressaltamos em Pollak (1992) que a memória é seletiva em duas extremidades, tratando de guardar as experiências que se constituam entre o positivo e 0 negativo, demonstrando como a representatividade social que cada indivíduo estabelece na discussão é relativa e depende dos fatores motivacionais no seu tempo e espaço atualizados. Acerca disso, o jogador 3 relatou:

Olha, eu trabalhava, eu acho que meu nome vai ter que ficar, vai ter que ficar [oculto no trabalho], vai ter que [risos]. Quando eu jogava futebol de salão aqui no Paraná Clube, tinha um treinador que ele era conhecido por isso sim, só com a molecada assim. [Pensando] Ele trazia meninos de fora e tal e ele tentou uma vez, mas foi, ele não tentou nem uma coisa assim, foi só uma coisa que ele chegou em mim e falou: 'Você sabe que as coisas podem ficar mais fáceis para você' e não sei o que e foi e pegou no meu pinto assim e aí depois disso eu parei de jogar salão. Eu ficava entre o salão e o campo, salão e o campo e aí depois dessa época que eu saí do salão, eu fui para o campo de vez, eu falei: 'Ah, não dá isso aí'. Mas tinha muito cara que não saía da casa dele assim [...]. Eu lembro que uma época eu cheguei, fui viajar com ele, ele não fez nada comigo na viagem assim, acho que ele ainda estava me ganhando. Aí ele me deu agasalho, me deu tênis, me deu um monte de coisa assim e volta e meia os caras sempre chegavam assim cheio de presentes assim do cara lá, a molecadinha. Daí tinha um cara que também ajudava ele lá e diz que os dois gostavam de molecadinha [...] Mas tem no meio do futebol, principalmente na categoria de base, muito, tem uns cara que trabalham com essas coisas (JOGADOR 3, 2016). 
Com base em Damo (2005) o processo de formação de atletas trata de uma competitividade que o autor denomina de "pés-de-obra", em que de alguma forma luta-se para ser escolhido e empreendido. De certa forma, isso estabelece para os atletas jovens uma base profissionalizada do esporte no que diz respeito a disciplina, empenho, dedicação e desempenho, mas que também perpassa pelas relações que estabelece com os demais agentes nesse meio.

O problema disso é que aqueles que aceitam a proposta do aliciador ocultam os fatos por se submeterem a esse tipo de relação, e os que não aceitam, como no caso do nosso colaborador, não têm maturidade suficiente para entender a gravidade desse tipo de situação e consequentemente denunciar esse tipo de crime.

As memórias operam com autonomia no tempo e no espaço, proporcionando uma representatividade social de acordo com a capacidade do indivíduo dar um significado coletivo, que se destaca a partir da relevância em que a narrativa se apresenta na história, bem como essas questões serão avaliadas pelo sujeito no tempo presente (BOSI, 2003).

As ideias de Candau (2014) acerca da localização no tempo e no espaço são ainda mais evidentes, já que notabilizam a diferença dos discursos nas duas narrativas. 0 jogador 3 inicia reiterando que será necessário ocultar seu nome na pesquisa, já que ainda é um atleta em atividade e esse tipo de polêmica pode trazer prejuízos públicos para o seu nome. Ao contrário, o jogador 2 , fora desse contexto, retratou sua história de forma explícita e sem receio de que suas experiências passadas pudessem prejudicá-lo.

No caso do jogador 3 , a precaução é válida, porque mesmo se tratando de uma história do passado, ainda pode afetar o seu presente, criando uma polêmica desnecessária para a carreira que ainda está em andamento. Nesse sentido, a formação narrativa é representada pela subjetividade do sujeito em consonância com sua localização dentro da estrutura no momento em que discursa (SMITH, 2012).

O atleta não se negou a relatar suas experiências acerca do tema, o que demonstrou seu comprometimento para com as expectativas deste trabalho, que visa desvelar essas obscuridades que permanecem veladas pelas fontes oficiais. Sua necessidade de se manter em sigilo compreende que esse discurso tem fundamento, evidenciando sua forma de pensar o problema. O colaborador nos aponta para o fato de que a inserção de sujeitos com capital simbólico nessas instituições permite a permanente ação criminosa contra menores de idade, que buscam no futebol a realização de seus objetivos esportivos, sendo ludibriados em troca de presentes e favores. 0 jogador 1 continuou:

Olha, comigo não aconteceu, sei de alguns casos de técnicos, que tinha que te pagar, ou uma situação outra pra entrar num clube: 'Ah se eu te colocar você, determinada situação', empresário, a gente fica sabendo, mundo da bola, moleque chega lá, sonho é jogar, daí faz o que for, né, às vezes pra conquistar o sonho de ser atleta. Mas assim, eu não presenciei nada, a gente fica sabendo de casos assim. Então, a gente fica sabendo através de outros que poderiam ser, mas eu nunca presenciei, sabe? Técnico, ou empresário de futebol ter uma conduta com meninos e tal, a gente ficava sabendo: 'Ah tem empresário, aquele lá não sei o quê'. Mas nunca tive uma, eu não presenciei nada, então não posso falar. Sim, sim, de técnicos e empresários [aliciamento sexual], mas que nem eu te falei, da minha parte eu não presenciei, pode ter acontecido com outros meninos? Pode. Aquela coisa: 'Ah, vou te mandar para a Europa, vou te colocar num time grande'. Histórias da bola, confirmado que algum amigo meu me falou, que aconteceu, 
falava sempre dos outros: 'Ah, acho que é, acho que não é, então melhor não ir com esse cara', não ter relação empresarial com o cara. 'Ah, esse técnico não sei o quê', técnico de equipes menores (JOGADOR 1, 2016).

Através de Spaggiari (2015) compreendemos que alguns desses aspirantes a atleta de futebol profissional fazem desse objetivo um planejamento familiar, em que a condição de baixa renda encontra no esporte uma possibilidade de ascensão social que por outra via talvez não fosse possível de ser alcançada.

Em que pesem as relações estabelecidas para chegar a uma posição dominante no que se refere a prestígio e dinheiro que advém de uma carreira bem-sucedida, alguns desses aspirantes a jogadores aceitam a condição inicial de inferioridade na "balança" de poder com dirigentes, técnicos e empresários e estabelecem uma relação de troca de favores.

Spaggiari (2008) denomina isso de sistema de trocas recíprocas, em que os futuros atletas têm seu percurso facilitado nesse campo concorrido, mas em contrapartida se submetem aos crimes de abuso sexual, ocasionando inclusive no apagamento dos casos e possibilitando a reincidência com outros jovens.

A narrativa evidencia a ideia de Pollak (1992) a respeito dos acontecimentos vividos por tabela, repassando histórias que ouviu falar, mesmo sem ter vivido essa experiência. Nesse caso, como se trata de uma polêmica, atentamos quanto às causas dessa memória ser exposta de forma retraída. A primeira foi sua entrevista ter sido acompanhada por uma série de outros indivíduos que não faziam parte da pesquisa ${ }^{5}$, o que pode ter causado um constrangimento em relação ao assunto e uma necessidade de ocultar detalhes que pudessem comprometer a si e a outros sujeitos que porventura fossem citados nessa discussão. Na segunda, destacamos a formação narrativa proposta por Smith (2012) e Bruner (2014) quanto à reação causada pela temática, em que o sujeito se mostrou incomodado com a questão, tentando silenciar a história.

Essa polêmica abordada com diferentes colaboradores em contextos distintos proporciona respostas diversas, as quais devem ser pensadas a partir de suas particularidades. Porém, é relevante pensarmos também que os discursos retratados nos mostram que, mesmo em momentos diferentes e situações específicas, o problema do assédio sexual é compartilhado por uma visão da coletividade, reiterando essa perspectiva da memória coletiva nesse cenário (HALBWACHS, 2013).

Nesse caso, o colaborador enfatiza por diversas vezes que não viveu aquela situação, notabilizando que apenas ficou sabendo de determinadas histórias, tentando não deixar de responder à pergunta, mas desvinculando qualquer perspectiva de relacionar sua imagem com esse tipo de fato. Mesmo de forma silenciada, sua narrativa entende que esse problema está presente no futebol e que esses indícios propostos pelas histórias que ouviu de outros indivíduos devem ser compreendidos como parte desse espaço, mesmo que seu discurso não estivesse disposto a colaborar para esse entendimento. 0 jogador 4 afirmou:

Não, cara, assim de treinador, de dirigente, aonde eu passei não teve nem no Coritiba, nem no Atlético com jogadores da minha idade, eu nunca presenciei isso aí. Eu soube de histórias de outras pessoas e tal, mas eu vivenciar isso com os amigos da minha idade nunca vivi. Ah, já soube, já soube sim, de caras dentro do Coritiba na época que tinha o diretor, não sei se era diretor ou presidente [...] que falavam que ele às vezes chegava no cara de conversinha fiada: 'Aí como você

5 Essa entrevista fez parte da minha avaliação em uma disciplina de História Oral na pós-graduação em Educação Física e teve o acompanhamento dos colegas matriculados no programa. 
é bonito e tal, vamos jantar comigo', acabava dando uma roupa para o cara, um tênis, coisas do tipo, em troca de uma relação ou alguma coisa assim com ele (JOGADOR 4, 2016).

Apoiados em Smith (2012) a respeito da formação narrativa, percebemos o silêncio ao retratar esse tema, já que precisamos insistir para o colaborador se posicionar a respeito. As temáticas polêmicas no contexto esportivo que denotam problemas sociais relevantes se caracterizam por serem algumas das discussões mais interessantes de abordarmos por meio das fontes orais, principalmente porque constituem como a memória é controversa (BOSI, 2003).

Dessa forma, alguns atletas preferem ocultar a ocorrência desses crimes com receio de serem incompreendidos e acabarem perdendo a chance de ter uma carreira profissional bem-sucedida, devido à influência desses dirigentes no clube e no meio esportivo de modo geral. A partir de Spaggiari (2009) entendemos que o sonho de ser jogador de futebol ter representatividade social e mudar a realidade financeira da família retrata os motivos de alguns problemas continuarem sendo abordados de forma velada no meio futebolístico, como nos ocultamentos de casos de assédio.

Além disso, compreendemos que as categorias de base dos clubes se tornam um espaço propício para que esses casos ocorram, haja vista se tratar de um lugar de circulação de jovens que ficam à mercê dos dirigentes, técnicos e empresários. Em alguns casos, esses indivíduos acabam adentrando nesse meio com intuito de cometer esses crimes, justamente por se colocarem em uma situação de disparidade de poder, utilizando-se de sua posição com 0 intuito de obter vantagens indevidas.

Como propõe Damo (2005), o futebol se configura como um espaço de múltiplas relações, que culturalmente denota a ideia de uma possibilidade de ascensão social através de uma prática lúdica que agrada parte dos jovens que o praticam em seus momentos livres. Por isso o meio futebolístico acaba se tornando visado na ocorrência desse tipo de crime, bem como no seu ocultamento e consequentemente na falta de punição dos infratores.

Ao enfatizarmos que essa questão não precisava ter acontecido com ele necessariamente, passamos a ter uma resposta mais concreta, mesmo que ainda com certa ressalva, pelo fato de ser um atleta em atividade atualmente e por compreender que sua inserção no futebol poderia prejudicá-lo. Portanto, a posição do sujeito no tempo e no espaço (CANDAU, 2014) dão indícios de que o trabalho com a História Oral favorece a reflexão do contexto, problematizando as hipóteses que fizeram o atleta não se aprofundar no tema.

Com base em Thompson (1992) percebemos como o contexto e as condições de produção do discurso influenciam na construção da narrativa. Percebemos isso ao comparar os discursos do jogador 2 e do jogador 4 , em que o primeiro, ao contrário do segundo, não está mais inserido no futebol, notabilizando suas experiências e as de indivíduos com os quais conviveu.

Por isso as fontes orais passam a contemplar mais do que apenas o conteúdo das transcrições. Tratam de uma busca constante pela subjetividade, que é afetada pelas condições de produção que acabam externando os problemas de acordo com a posição na estrutura. Percebemos então, que apesar dos dois indivíduos afirmarem conhecer casos de assédio sexual nas categorias de base, enfatizando o problema como de ordem social e coletiva, apenas um tratou a questão com maior profundidade. 


\section{CONSIDERAÇÕES FINAIS}

Compreendemos que as oralidades promoveram uma versão da história que não pode ser contemplada nas fontes oficiais e que enriquece cientificamente as discussões do futebol, justamente por abordá-lo em uma perspectiva subjetiva, visto que os detalhes, as emoções, os ocultamentos, os gestos, a entonação da voz e a reinterpretação que os colaboradores apresentaram em suas memórias nos ajudaram a compreender acerca dos casos de assédio sexual vividos ou presenciados por esses sujeitos.

Problemas sociais como esse compreendem perspectivas relevantes no retrato da realidade e que, em alguns casos, não são contemplados na proporção devida pelas fontes oficiais. Nesse sentido, o jogador 2 e o jogador 3 apontaram abertamente o problema através das experiências vividas enquanto jovens atletas. Para o jogador 2 isso foi mais evidente, visto que ele não está mais inserido na estrutura e se propôs a dialogar sobre tudo que atribuiu significado em sua carreira e que sua memória conseguiu notabilizar. As subjetividades enfatizaram as singularidades de cada caso, mas assim como em outros momentos, perspectivaram uma discussão social acerca desse problema e de possíveis reincidências silenciadas em diversas oportunidades.

O problema também é compartilhado pelo jogador 1 e pelo jogador 4, porém, eles se esquivaram a respeito do assunto e enfatizaram que esse tipo de situação não aconteceu com eles, se tratando de uma memória vivida por tabela. A subjetividade permeou o discurso de maneira que os sujeitos podem ter ocultado detalhes de que porventura sua memória não recordou, ou que conscientemente não queriam revelar. Identificando através de suas reações, como compreenderam essas polêmicas, evidenciando que os problemas se consolidaram no meio futebolístico, mesmo que não tenham atribuído representatividade que os fizessem discursar abertamente sobre isso.

Compreendemos então que a oralidade trata da singularidade de cada narrativa, visto que as histórias são contadas a partir do ponto de vista de quem, de alguma forma, as vivenciou. Entretanto, a reincidência de casos referentes a um problema social em evidência que anteriormente permanecia velado reitera que casos de assédio sexual a esportistas de alto rendimento menores de idade já aconteciam, e por vezes passavam despercebidos pela mídia e pelas autoridades responsáveis em coibir esse tipo de ação criminosa. No caso desta pesquisa, nenhum dos entrevistados assumiu ter aceitado 0 assédio, endossando 0 caráter delicado e estigmatizado de sujeitos vítimas desse crime.

\section{REFERÊNCIAS}

ALBERTI, Verena. 0 fascínio do vivido, ou o que atrai na história oral. Rio de Janeiro: CPDOC, 2003.

BOSI, Eclea. 0 tempo vivo da memória: ensaios de psicologia social. São Paulo: Ateliê, 2003.

BOURDIEU, Pierre. O Poder Simbólico. Rio de Janeiro: Bertrand Brasil, 1992. 
BRUNER, Jerome. Fabricando histórias: Direito, literatura, vida. São Paulo: Letra e Voz, 2014.

CANDAU, Joël. Memória e identidade. São Paulo: Contexto, 2014.

DAMO, Arlei Sander. Do dom à profissão: uma etnografia do futebol de espetáculo a partir da formação de jogadores no Brasil e na França. 2005. 435p.Tese (Doutorado em Antropologia Social) - Instituto de Filosofia e Ciências Humanas, UFRGS, Porto Alegre-RS, 2005.

DAMO, Arlei Sander. Dom, amor e dinheiro no futebol espetáculo. Revista Brasileira de Ciências Sociais, v.23, n. 66, p. 139 - 150, fev. 2008.

FERREIRINHA, Isabella Maria Nunes; RAITZ, Tânia Regina. As relações de poder em Michel Foucault: reflexões teóricas. RAP, v.44, n.2, p. 367-383, mar./abr. 2010.

HALBWACHS, Maurice. A memória coletiva. São Paulo: Centauro, 2013.

PATAI, Daphne. História oral, feminismo e política. São Paulo: Letra e Voz, 2010.

POLLAK, Michael. Memória e identidade social. Estudos históricos, v. 5, n. 10, p. 200 $2012,1992$.

POLLAK, Michael. Memória, esquecimento, silêncio. Estudos históricos, v. 2, n. 3, p. 3 - 15, 1989.

PORTELLI, Alessandro. A filosofia e os fatos: narração, interpretação e significado nas

memórias e nas fontes orais. Tempo, v. 1, n. 2, p. 59-72, 1996.

PORTELLI, Alessandro. Ensaios de história oral. São Paulo: Letra e Voz, 2010.

PORTELLI, Alessandro. O que faz a história oral diferente. Projeto História, n.14, p.25 - 39, fev. 1997.

SMITH, Richard Cándida. Circuitos de subjetividade: História oral, o acervo e as artes. São Paulo: Letra e Voz, 2012.

SPAGGIARI, Enrico. Família joga bola: constituição de jovens futebolistas na várzea paulistana. 2015. 470 f. Tese (Doutorado em Antropologia Social) - Faculdade de Filosofia, Letras e Ciências Sociais, São Paulo, USP, 2015.

SPAGGIARI, Enrico. Ganhar jogo, pagar jogo e ganhar visita: prática futebolística em um bairro rural. Horizontes Antropológicos, ano 14, n. 30, p. 165-190, jul./dez. 2008.

SPAGGIARI, Enrico. Tem que ter categoria: construção do saber futebolístico. 2009. 265 f. Dissertação (Mestrado em Antropologia Social) - Departamento de Antropologia da Faculdade de Filosofia, Letras e Ciências Humanas, São Paulo, USP, 2009.

THOMPSON, Paul. A voz do passado. São Paulo: Paz e Terra, 1992.

\section{Apoio:}

Coordenação de Aperfeiçoamento de Pessoal de Nível Superior - Brasil (CAPES) - Código de Financiamento 001. This study was financed in part by the Coordenação de Aperfeiçoamento de 